\title{
Biofuel Manufacturing from Woody Biomass: Effects of Sieve Size Used in Biomass Size Reduction
}

\author{
Meng Zhang, ${ }^{1}$ Xiaoxu Song, ${ }^{1}$ T. W. Deines, ${ }^{1}$ Z. J. Pei, ${ }^{1}$ and Donghai Wang ${ }^{2}$ \\ ${ }^{1}$ Department of Industrial and Manufacturing Systems Engineering, Kansas State University, Manhattan, KS 66506, USA \\ ${ }^{2}$ Department of Biological and Agricultural Engineering, Kansas State University, Manhattan, KS 66506, USA
}

Correspondence should be addressed to Z. J. Pei, zpei@ksu.edu

Received 19 December 2011; Accepted 9 March 2012

Academic Editor: Kazim Husain

Copyright () 2012 Meng Zhang et al. This is an open access article distributed under the Creative Commons Attribution License, which permits unrestricted use, distribution, and reproduction in any medium, provided the original work is properly cited.

\begin{abstract}
Size reduction is the first step for manufacturing biofuels from woody biomass. It is usually performed using milling machines and the particle size is controlled by the size of the sieve installed on a milling machine. There are reported studies about the effects of sieve size on energy consumption in milling of woody biomass. These studies show that energy consumption increased dramatically as sieve size became smaller. However, in these studies, the sugar yield (proportional to biofuel yield) in hydrolysis of the milled woody biomass was not measured. The lack of comprehensive studies about the effects of sieve size on energy consumption in biomass milling and sugar yield in hydrolysis process makes it difficult to decide which sieve size should be selected in order to minimize the energy consumption in size reduction and maximize the sugar yield in hydrolysis. The purpose of this paper is to fill this gap in the literature. In this paper, knife milling of poplar wood was conducted using sieves of three sizes (1, 2, and $4 \mathrm{~mm})$. Results show that, as sieve size increased, energy consumption in knife milling decreased and sugar yield in hydrolysis increased in the tested range of particle sizes.
\end{abstract}

\section{Introduction}

The transportation sector of the United States accounts for over $70 \%$ of the nation's total petroleum consumption, and $57 \%$ of the petroleum is imported [1]. In addition, use of petroleum-based fuels contributes to accumulation of greenhouse gases (GHG) in the atmosphere. Due to concerns of energy security and GHG emissions, it becomes crucial to develop domestic sustainable alternatives to petroleum-based transportation fuels [2].

Biofuels produced from cellulosic biomass (herbaceous, woody, and generally inedible portions of plant matter) are a sustainable alternative to petroleum-based fuels. The United States has the resource to produce over 1 billion dry tons of biomass with more than $80 \%$ of cellulosic biomass including about 320 million dry tons of woody biomass annually $[5,6]$. This amount of biomass is sufficient to produce 90 billion gallons of liquid fuels that can replace about $30 \%$ of the nation's current annual consumption of petroleum-based transportation fuels [6]. In contrast to grain-based biofuels, cellulosic biofuels do not compete for the limited agricultural land with food or feed production [7].

Figure 1 shows the major processes of converting woody biomass to ethanol (the most common form of biofuels). Size reduction reduces the particle size of woody biomass. Pretreatment helps to make cellulose in the biomass more accessible to enzymes during hydrolysis. Hydrolysis depolymerizes cellulose into its component sugars (glucose). Afterwards, fermentation converts glucose into ethanol [3].

Size reduction of woody biomass is necessary because large-size woody biomass cannot be converted to biofuels efficiently with the current conversion technologies [8-10]. Size reduction of woody biomass usually involves two steps. The first step is wood chipping [11]. Machines available for wood chipping include disk, drum, and V-drum chippers [12-14]. Figure 2 illustrates a disk chipper. Straight knives are mounted on a flywheel that revolves at a speed ranging from 400 to 1000 revolutions per minute (rpm). A wood log 


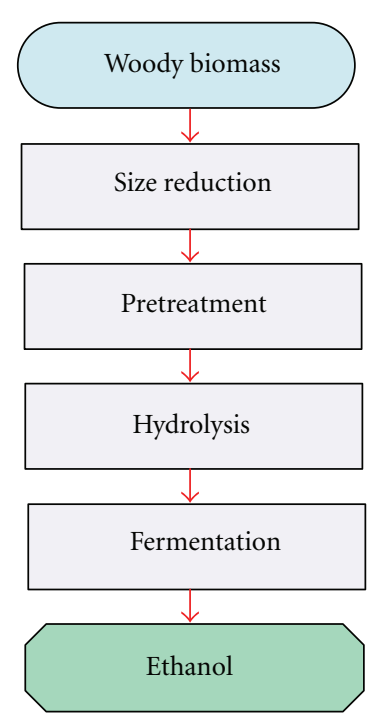

FIGURE 1: Major processes of converting woody biomass to ethanol (after [3]).

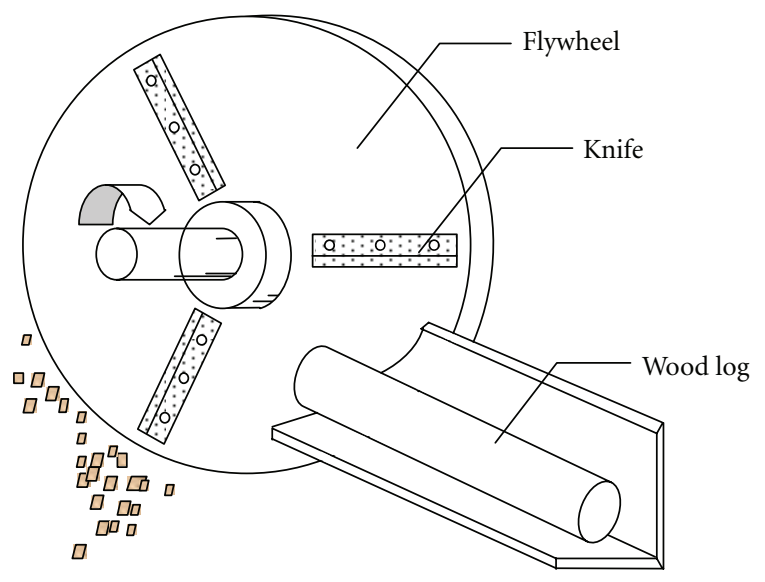

FIGURE 2: Illustration of a disk chipper (after [4]).

is fed to the disk chipper. Wood chips produced by wood chipping usually have sizes ranging from 5 to $50 \mathrm{~mm}$ [4]. Energy consumption of this step is typically about $0.05 \mathrm{Wh} / \mathrm{g}$ [15].

The second step is biomass milling to further reduce the wood chips into small particles. This step is usually conducted on knife mills [16] or hammer mills [17-19]. Wood particles produced by biomass milling usually have sizes ranging from 0.1 to $10 \mathrm{~mm}$ [19]. Energy consumption of this step ranged from 0.15 to $0.85 \mathrm{Wh} / \mathrm{g}[15,20,21]$.

Sieves are installed on knife mills and hammer mills to control the size of wood particles. During biomass milling, wood particles that are smaller than the sieve size (the size of the openings on a sieve) will pass through the sieve; those larger than the sieve size will be recirculated and milled further. In this study, sieves and sieve size are reserved to describe the sieves installed on knife mills or hammer mills.

There are reported studies about the effects of sieve size on energy consumption in woody biomass milling using

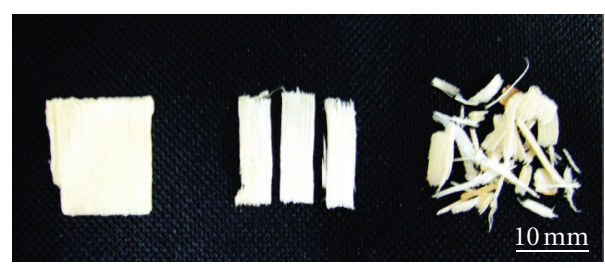

FIgURE 3: Examples of large, medium, and small wood chips.

knife mills or hammer mills. A consistent observation was that energy consumption increased dramatically as sieve size became smaller [22-24]. However, these reports did not present sugar yield (proportional to ethanol yield) results using the wood particles produced by biomass milling. It was reported that woody biomass with smaller particle size had higher sugar yield [25-28]. However, particle size in these reported studies was defined differently from the sieve size in this paper. In these studies, wood particles produced by knife mills or hammer mills using a certain sieve size were separated into several size ranges by the screening method. The term particle size was actually the particle size range determined by the sizes of the openings on the screens. In this paper, the size of the openings on the screen is called screen size. Moreover, previously reported studies did not present energy consumption data for the biomass milling process used to produce the wood particles from which the sugar yield measurements were performed.

The lack of comprehensive studies about the effects of sieve size on energy consumption in size reduction (biomass milling) and sugar yield in hydrolysis makes it difficult to decide which sieve size should be selected in order to minimize the energy consumption in size reduction and maximize the sugar yield in hydrolysis. The purpose of this study is to fill this gap in the literature by studying the effects of sieve size on energy consumption in size reduction and sugar yield in hydrolysis simultaneously.

\section{Experimental Conditions and Procedures}

2.1. Biomass Material Preparation. Poplar wood chips were purchased from Petco Animal Supplies, Inc. (Manhattan, KS, USA). Since the purchased wood chips had a wide distribution in size, the wood chips were separated into three groups using two screens with screen size of 5 and $12.5 \mathrm{~mm}$, respectively. Large chips are those that did not pass through the $12.5 \mathrm{~mm}$ screen. Small chips are those that passed through the $5 \mathrm{~mm}$ screen. Medium chips are those that passed through the $12.5 \mathrm{~mm}$ screen but not the $5 \mathrm{~mm}$ screen. Examples of large, medium, and small wood chips are shown in Figure 3. Only the medium wood chips were used in this study.

The moisture content of the wood chips (as purchased) was $1.2 \%$, measured by following the ASAE Standard S358.2 [29]. To adjust the moisture content of wood chips to a desired level, distilled water was added (by spraying evenly) to the wood chips. To achieve wood chips of $10 \%$ and $18 \%$ moisture content, 96 and $233 \mathrm{~mL}$ distilled water was added 


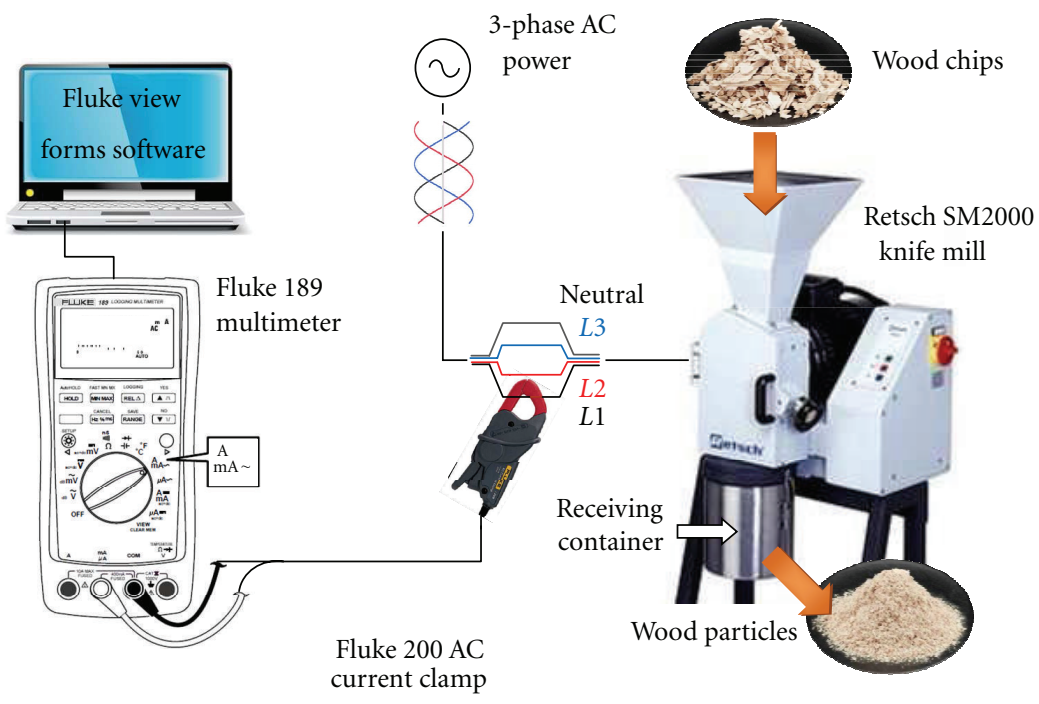

FIgURE 4: Experimental setup for knife milling of wood chips.

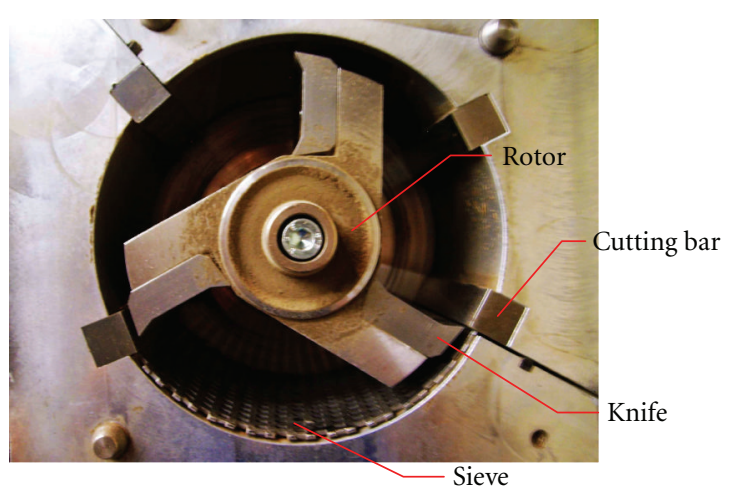

FIGURE 5: Milling chamber of the knife mill.

per $1000 \mathrm{~g}$ of original wood chips, respectively. After moisture content adjustment, the wood chips were placed in the sealed Ziploc bags and stored in a refrigerator at $4^{\circ} \mathrm{C}$ for at least 72 hours before knife milling.

\subsection{Experimental Setup and Procedure for Knife Milling. The} experimental setup for knife milling of wood chips is illustrated in Figure 4. A Retsch knife mill (model no. SM 2000, Retsch GmbH, Haan, Germany) was used. It was equipped with a three-phase $1.5 \mathrm{~kW}$ electric motor. The rotation speed of the motor was $1720 \mathrm{rpm}$. Figure 5 shows the milling chamber of the knife mill. Three knives (95 mm long and $35 \mathrm{~mm}$ wide) were mounted on the rotor inside the milling chamber. Four cutting bars were mounted on the inside wall of the milling chamber. Wood chips was cut into particles between the knives and the cutting bars. The gap between a knife and a cutting bar was $3 \mathrm{~mm}$. A sieve $(145 \mathrm{~mm}$ long and $98 \mathrm{~mm}$ wide) was mounted at the bottom of the milling chamber. Sieves with three sieve sizes $(4,2$, and $1 \mathrm{~mm}$, resp.), as shown in Figure 6, were used in this study.

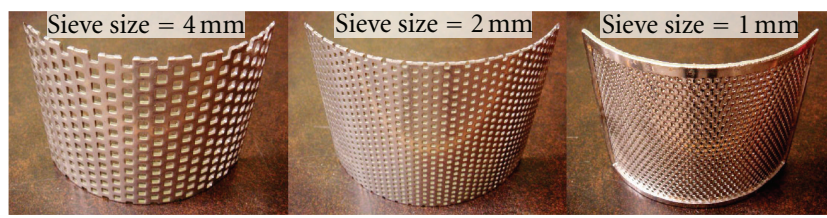

FIGURE 6: Sieves used in knife milling.

Sieve sizes of 1 and $4 \mathrm{~mm}$ were selected because they were the minimum and maximum sieve size, respectively, that could be practically investigated in this study. As described in Section 2.1, the wood chips prior to milling had a range of 5 to $12.5 \mathrm{~mm}$. If any available sieve size larger than $4 \mathrm{~mm}$ was used, some of the wood chips would fall through the sieve without being cut. Furthermore, based on previous experience, if any available sieve size smaller than $1 \mathrm{~mm}$ (the next one was $0.5 \mathrm{~mm}$ ) was used, some of the sieve openings would be blocked by milled particles, causing significant increase in milling time and energy consumption.

At the beginning of each test, the knife mill was run for 10 seconds before loading any wood chips to avoid the current spike (this would happen if the knife mill started with wood chips already in the milling chamber). Then, $50 \mathrm{~g}$ of wood chips were loaded into the knife mill. This amount of wood chips was enough to keep the milling chamber approximately full (in volume). During knife milling, more wood chips were loaded into the milling chamber using a scoop as shown in Figure 7. The amount of wood chips loaded by the scoop at each time was $5 \pm 1 \mathrm{~g}$. These additional wood chips were loaded at a rate that would keep the milling chamber approximately full (in volume) but without causing over loading.

In each test, the total amount of wood chips loaded into the milling chamber was $200 \mathrm{~g}$. The milling time was different under different conditions. When a smaller sieve size 


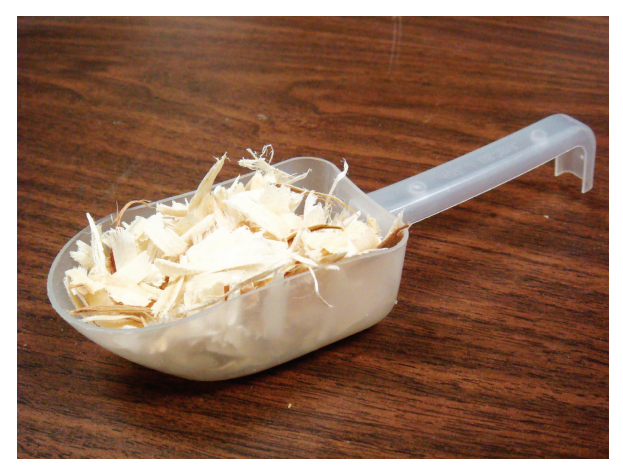

FIGURE 7: The scoop used for loading wood chips.

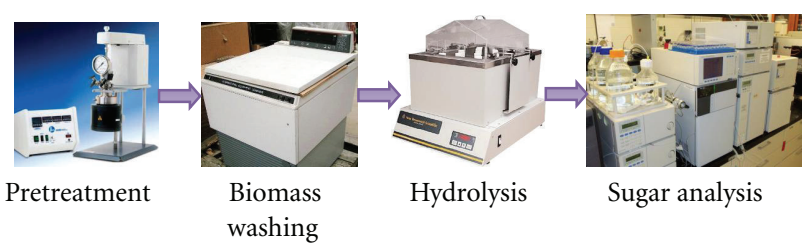

FIGURE 8: Four steps in sugar yield measurement.

TABLe 1: Experimental conditions.

\begin{tabular}{lcc}
\hline Condition ID & $\begin{array}{c}\text { Moisture content } \\
(\%)\end{array}$ & $\begin{array}{c}\text { Sieve size } \\
(\mathrm{mm})\end{array}$ \\
\hline 1 & 1.2 & 1 \\
2 & 1.2 & 2 \\
3 & 1.2 & 4 \\
4 & 10 & 1 \\
5 & 10 & 2 \\
6 & 10 & 4 \\
7 & 18 & 1 \\
8 & 18 & 2 \\
9 & 18 & 4 \\
\hline
\end{tabular}

was used, it took a longer time to mill the same amount of wood chips.

After each test, wood particles in the receiving container were collected, weighed, and kept in the sealed Ziploc bags. The amount of wood particles collected by the receiving container in each test was less than $200 \mathrm{~g}$, because some wood chips (or particles) did not pass through the sieve yet when the knife mill was turned off. Before starting the next test, the milling chamber was opened and any remaining wood chips were cleaned using a brush. To allow the motor to cool down, there was a waiting period (at least five minutes) between two successive tests. Experimental conditions are listed in Table 1.

\section{Evaluation Parameters and Measurement Procedures}

3.1. Energy Consumption. In this study, energy consumption is the electricity consumed by the electric motor of the knife mill. As shown in Figure 4, electric current to the motor was measured using a Fluke 189 multimeter and a Fluke 200 AC current clamp (Fluke Corp., Everett, WA, USA). Current data were collected using Fluke View Forms software. The sampling rate was 2 readings per second. Data acquisition began after the first $50 \mathrm{~g}$ of wood chips was loaded into the milling chamber and stopped when additional $150 \mathrm{~g}$ of wood chips was all loaded into the chamber. The knife mill was turned off right after data acquisition stopped.

The software recorded the average current $\left(I_{\mathrm{AVE}}\right)$ in each test. The voltage $\left(V_{\mathrm{LN}}\right)$ was $208 \mathrm{~V}$. The energy consumed during each test (that lasted for $\mathrm{t}$ seconds) $\left(E_{t}\right)$ was calculated using the following [31]:

$$
E_{t}=\frac{\sqrt{3} \cdot I_{\mathrm{AVE}} \cdot V_{\mathrm{LN}} \cdot t}{3600}(\mathrm{Wh}) .
$$

Dividing $E_{t}$ by the weight $(w)$ of the wood particles collected from the receiving container after the test gives energy consumption $(E)$ per unit weight, as expressed in (2):

$$
E=\frac{E_{t}}{w}\left(\frac{\mathrm{Wh}}{\mathrm{g}}\right) .
$$

3.2. Sugar Yield. Sugar yield in hydrolysis is the amount of glucose produced from hydrolyzing cellulose using enzymes. It was expressed as the concentration of glucose $(\mathrm{mg} / \mathrm{mL})$ in the measurement sample. Figure 8 shows the four steps in sugar yield measurement. In this study, $10 \mathrm{~g}$ of biomass and $200 \mathrm{~mL}$ of $2 \%$ sulfuric acid were loaded in the $600 \mathrm{~mL}$ vessel of a Parr pressure reactor (Model 4760A, Parr Instrument Co., Moline, IL, USA). Pretreatment time was 30 minutes, and pretreatment temperature was $140^{\circ} \mathrm{C}$.

After pretreatment, biomass was washed with hot distilled water using a centrifugal (Model PR-7000 M, International Equipment Co., Needham, MA, USA). The purpose of biomass washing was to remove the acid residues and inhibitors (substances that would bind to enzymes and decrease their activity to depolymerize cellulose to glucose [32]) formed during pretreatment. The rotation speed of the centrifugal was $4500 \mathrm{rpm}$. Each biomass sample was washed three times, and each time lasted for 15 minutes.

Accellerase 1500 (Danisco US Inc., Rochester, NY, USA) enzyme complex was used for hydrolysis of wood particles into sugars in solution with sodium acetate buffer $(50 \mathrm{mM}$, $\mathrm{pH} 4.8)$ and $0.02 \%(\mathrm{w} / \mathrm{v})$ sodium azide to prevent the microbial growth during hydrolysis. Enzymatic hydrolysis was carried out in $125 \mathrm{~mL}$ flasks with $50 \mathrm{~mL}$ of slurry in the water bath shaker (Model C76, New Brunswick Scientific, Edison, NJ, USA) with agitation speed of $110 \mathrm{rpm}$ at $50^{\circ} \mathrm{C}$ for 72 hours. The dry mass content of the hydrolysis slurries was $5 \%(\mathrm{w} / \mathrm{v})$ and the enzyme loading was $1 \mathrm{~mL} / \mathrm{g}$ of dry biomass. After enzymatic hydrolysis, samples were ready for sugar analysis.

Sugar analysis was done using an HPLC (Shimadzu Corp., Kyoto, Japan) equipped with an RPM-monosaccharide column $(300 \times 7.8 \mathrm{~mm}$; Phenomenex, Torrance, CA, USA) and a refractive index detector (RID-10A, Shimadzu, Kyoto, Japan). The mobile phase was $0.6 \mathrm{~mL} / \mathrm{min}$ of doubledistilled water, and oven temperature was $80^{\circ} \mathrm{C}$. HPLC can 


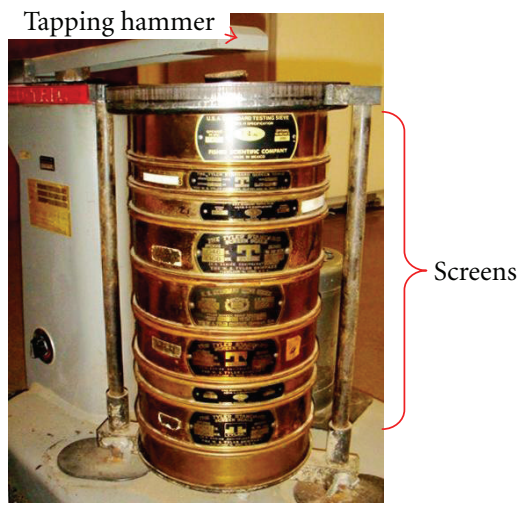

FIgURE 9: W.S. Tyler screen shaker.

identify and quantify individual components of a liquid mixture [33].

3.3. Particle Size Distribution. Wood particles produced by knife milling were not uniform in their size. Particle size distribution was determined using a screen shaker (Model RO-TAP 8" RX-29, W.S. Tyler Industrial Group, Mentor, $\mathrm{OH}, \mathrm{USA}$ ) as illustrated in Figure 9. A stack of screens from the bottom to the top were arranged from the smallest to the largest in screen size. The screen sizes used were $0.1,0.2,0.4$, $0.6,1.2,2.4,5.6$, and $6.3 \mathrm{~mm}$. A pan (no openings) was put at the bottom of these screens. $100 \mathrm{~g}$ of wood particles was loaded onto the top screen.

The screen shaker provided circular motion to the stack of screens at the rate of $278 \mathrm{rpm}$. Simultaneously, the tapping hammer hit the top of the stack at the frequency of 150 times per minute. The screen shaker was on for 5 minutes. Afterwards, wood particles retained on each screen were collected and weighed. The percentage of the wood particles in each of the nine particle size ranges $(<0.1,0.1-0.2,0.2-0.4$, $0.4-0.6,0.6-1.2,1.2-2.4,2.4-5.6,5.6-6.3$, and $>6.3 \mathrm{~mm}$ ) was translated to particle size distribution [34].

\section{Results and Discussion}

4.1. Energy Consumption in Knife Milling. Figure 10 shows energy consumption in knife milling of wood chips. Energy consumption decreased dramatically with an increase of sieve size. For instance, when knife milling of wood chips with moisture content of $1.2 \%$, energy consumption was as high as $1.38 \mathrm{Wh} / \mathrm{g}$ for $1 \mathrm{~mm}$ sieve size and only $0.16 \mathrm{Wh} / \mathrm{g}$ for $4 \mathrm{~mm}$ sieve size. The same trend was observed for the other two levels of moisture content.

In the literature, there are no reports about the effects of sieve size on energy consumption in knife milling of poplar wood chips. Phanphanich and Mani [35] used a knife mill (of the same model as the one used in this study) to reduce the size of pine wood chips (including chips, branches, barks, leaves, and small particles). The moisture content of the pine wood chips was $10 \%$. Only one sieve size $(1.5 \mathrm{~mm})$ was used in their study. Energy consumption in knife milling was $0.25 \mathrm{Wh} / \mathrm{g}$. Miao et al. [23] measured energy consumption in hammer milling of willow wood chips. The hammer mill was manufactured by Sears Roebuck and Co. (Hoffman Estates, IL, USA). The size of the willow wood chips (three dimensions) was 13-50, 13-76, and 5-25 mm. The moisture content was 7-10\%. Energy consumption in hammer milling using the 1,2 , and $4 \mathrm{~mm}$ sieves was $1.55,0.66$, and $0.39 \mathrm{Wh} / \mathrm{g}$, respectively.

Moisture content of poplar wood chips also affected energy consumption in knife milling. As shown in Figure 11, energy consumption in knife milling increased when moisture content increased from $1.2 \%$ to $10 \%$ and decreased slightly when moisture content increased from $10 \%$ to $18 \%$.

The literature does not have any reports about the effects of moisture content on energy consumption in knife milling of wood chips using the knife mill of the same model as the one used in this study. However, there are reports on these effects in knife milling of herbaceous biomass (such as miscanthus, switchgrass, and wheat straw). Miao et al. [23] investigated energy consumption in knife milling of miscanthus and switchgrass using the same model of knife mill. It was found that when moisture content increased from $7-$ $10 \%$ to $15 \%$, energy consumption in knife milling increased significantly. The same trend was also found in size reduction of wheat straw, barley straw, corn stover, and switchgrass using a hammer mill [36]. According to Mani et al. [36], an increase in moisture content of cellulosic biomass would increase the shear strength of the biomass; therefore, more energy was consumed in milling of cellulosic biomass.

4.2. Sugar Yield. Materials used for sugar yield evaluation were the particles produced by knife milling of wood chips with the moisture content of $1.2 \%$. For each sieve size, there were two independent samples processed for sugar yield evaluation. Figure 12 shows the sugar yield results. The results showed that wood particles processed using the $4 \mathrm{~mm}$ sieve had the highest sugar yield while sugar yields of wood particles processed using the 1 and $2 \mathrm{~mm}$ sieves were approximately the same.

There are reported investigations on the effects of sieve size on sugar yield. Zhang et al.'s results [30] are shown in Figure 13. Wheat straw particles milled using the $2 \mathrm{~mm}$ sieve had higher sugar yield than those milled using the $1 \mathrm{~mm}$ sieve. The knife mill used was the same model as the one in this paper. Similar results were reported by Theerarattananoon et al. [37]. In their work, wheat straw, corn stover, and big bluestem were milled using a hammer mill (Model 18-7300, Schuttle-Buffalo Hammermill, Buffalo, NY, USA) using 3.2 and $6.5 \mathrm{~mm}$ sieves. For these three types of cellulosic materials, biomass particles milled using the $6.5 \mathrm{~mm}$ sieve yielded more sugar than those milled using the $3.2 \mathrm{~mm}$ sieve (Figure 14). Both these reported studies involved a pelleting process (agglomerating biomass particles produced by milling into pellets) before sugar yield.

Figures 15 and 16 show the effects of woody biomass particle size on sugar yield reported in the literature. In Dasari and Berson's study [27], red oak saw dust was screened into four particle size ranges. As shown in Figure 15, particles in the size range of $0.03-0.08 \mathrm{~mm}$ yielded $80 \%$ more sugar than 


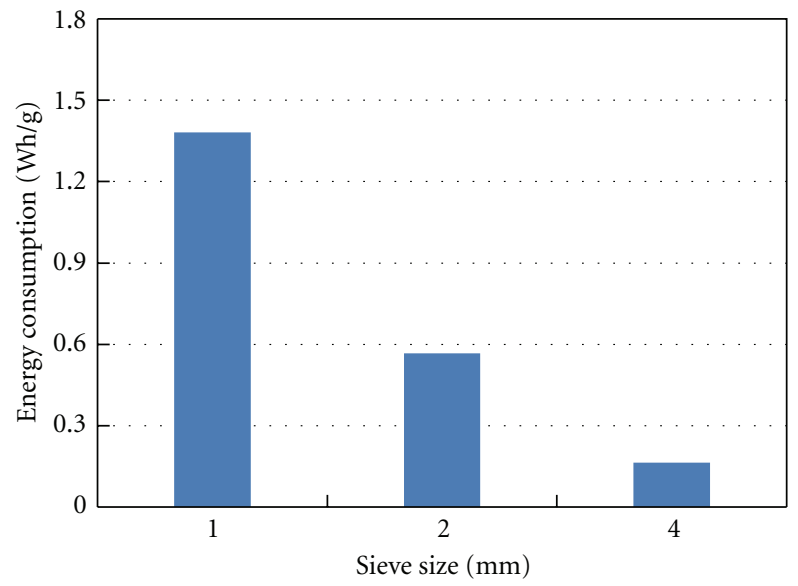

(a) Moisture content $=1.2 \%$

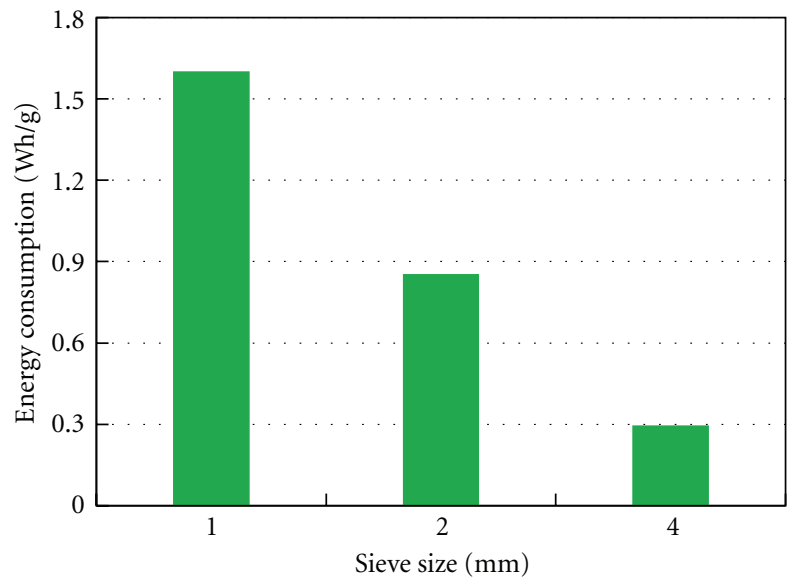

(b) Moisture content $=10 \%$

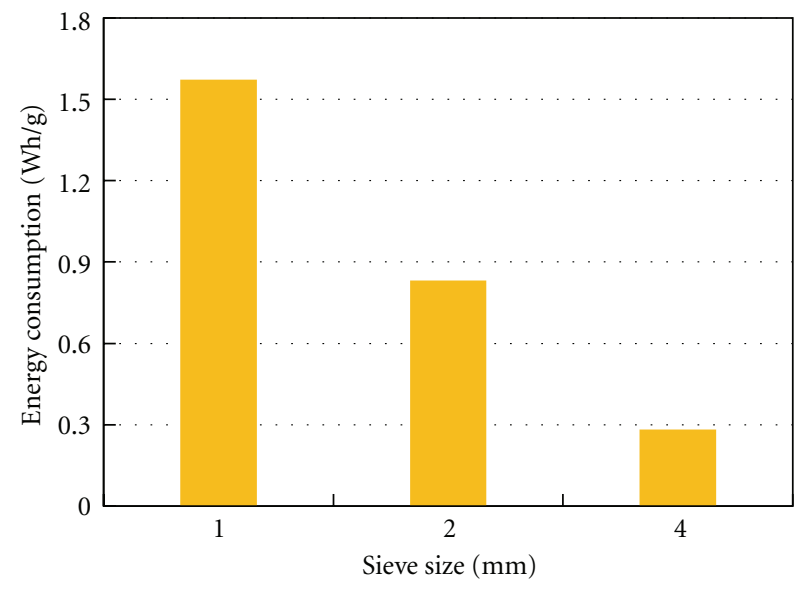

(c) Moisture content $=18 \%$.

FIGURE 10: Effects of sieve size on energy consumption in knife milling

those in the size range of $0.59-0.85 \mathrm{~mm}$. In Zhu et al.'s study [26], spruce wood chips were hammer milled in three successive steps using sieve sizes of $12.7,4.8$, and $0.8 \mathrm{~mm}$, respectively. After hammer milling, particles were screened into four particle size ranges. As shown in Figure 16, particles in the size range of smaller than $0.32 \mathrm{~mm}$ yielded 1.6 times more sugar than those in the size range of larger than $1.27 \mathrm{~mm}$.

Figure 17 shows the wood particles produced by knife milling using the three different sieve sizes $(4,2$, and $1 \mathrm{~mm}$ resp.). The particles produced using the same sieve did not have a uniform size. Their size distribution is shown in Figure 18. Similar distributions were reported by Himmel et al. [24]. In Himmel et al.'s study, poplar wood chips were processed by a knife mill (Mitts \& Merrill Frömag Group, Harvard, IL, USA) using $1 / 16,1 / 8$, and $3 / 32$ inch $(1.59,3.18$, and $2.38 \mathrm{~mm}$ ) sieves.

The results from this study and the studies conducted by Zhang et al. [30] and Theerarattananoon et al. [37] show that biomass particles produced with larger sieve size had higher sugar yield. However, results reported by Dasari and Berson [27] and Zhu et al. [26] show that wood particles in the smaller size range had higher sugar yield. At this point in time, the authors could not explain such inconsistence.
However, some differences in test conditions were noticed. In the studies reported by Dasari and Berson [27] and Zhu et al. [26], wood particles were from relatively narrow size ranges. In this work, wood particles were mixtures of particles that had a wide distribution in size. Further investigations will be carried out to study the effects of particle size distribution on woody biomass sugar yield.

\section{Conclusions and Future Work}

In this study, effects of sieve size on energy consumption in knife milling of poplar wood chips and sugar yield in hydrolysis were studied. The following conclusions are drawn. Energy consumption in knife milling increased dramatically as sieve size became smaller. Poplar wood particles processed by knife milling using the $4 \mathrm{~mm}$ sieve had higher sugar yield than those processed by knife milling using the 1 and $2 \mathrm{~mm}$ sieves.

Knife milling of wood chips using the $4 \mathrm{~mm}$ sieve consumed less energy in size reduction than using the 1 and $2 \mathrm{~mm}$ sieves. The wood particles knife milled using the $4 \mathrm{~mm}$ sieve had higher sugar yield in hydrolysis than those milled using the 1 and $2 \mathrm{~mm}$ sieves. This finding is very important 


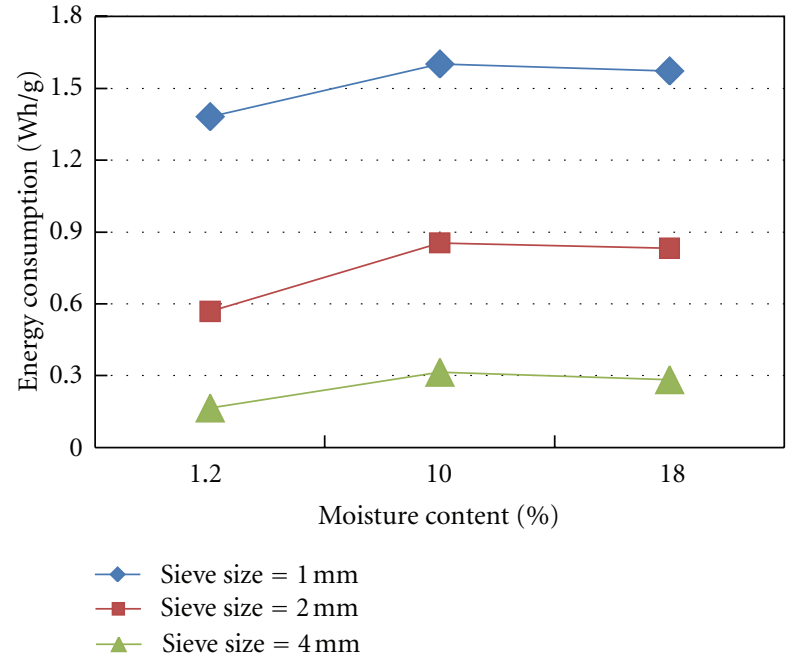

FIGURE 11: Effects of moisture content on energy consumption in knife milling.

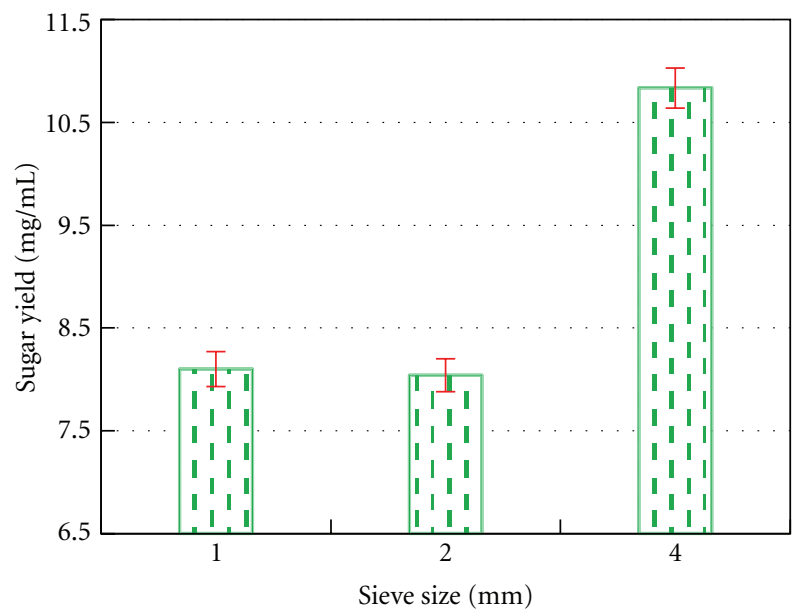

FIGURE 12: Effects of sieve size on sugar yield.

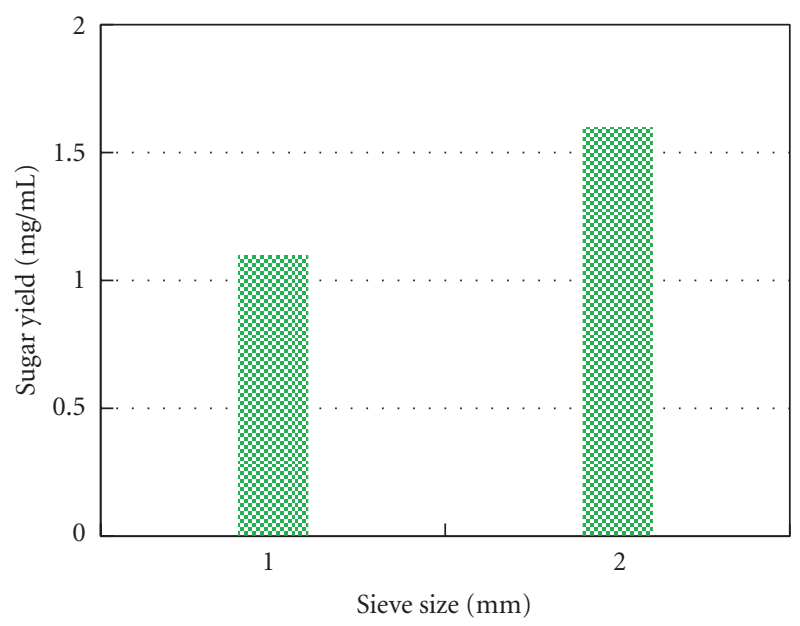

Figure 13: Effects of sieve size on sugar yield reported by Zhang et al. [30].

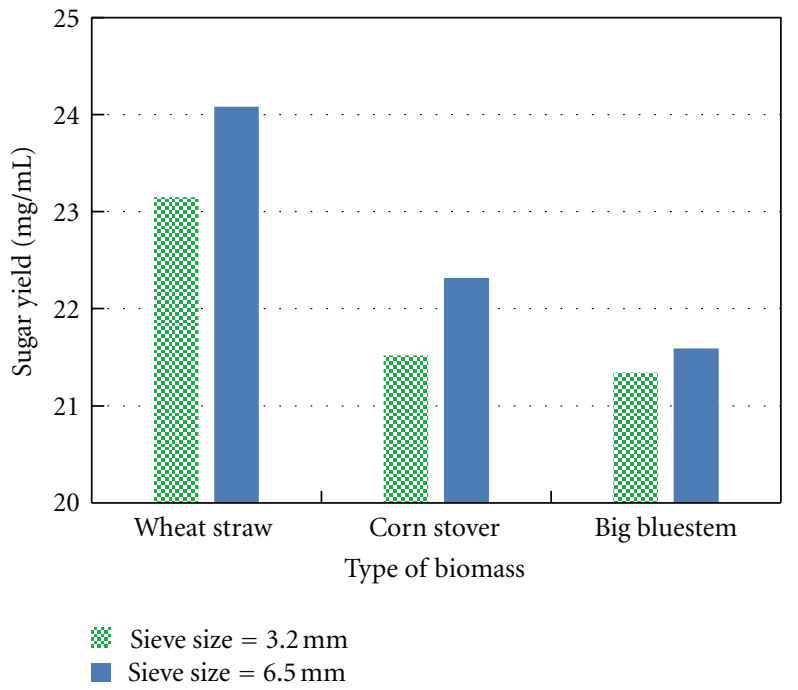

FIGURE 14: Effects of sieve size on sugar yield reported by Theerarattananoon et al. [37].

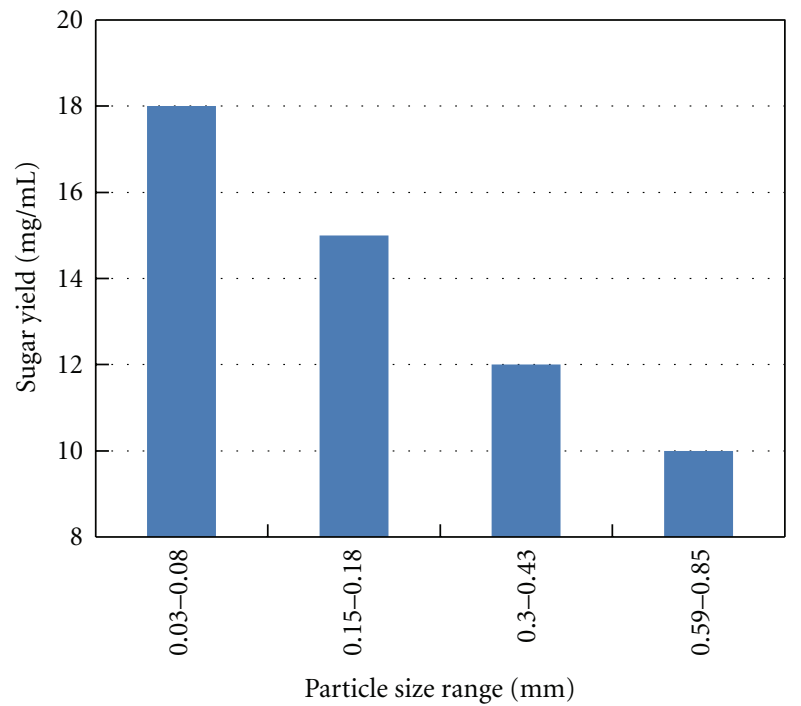

FIGURE 15: Effects of particle size on sugar yield reported by Dasari and Berson [27].

when deciding what sieve size is to be used in knife milling of wood chips to minimize energy consumption in size reduction and maximize sugar productivity in hydrolysis. In future study, the authors will also use $0.25,0.5$, and $8 \mathrm{~mm}$ sieves to further investigate the effects of sieve size on energy consumption in size reduction and sugar yield in hydrolysis. A hammer mill will be utilized to see if similar results can be obtained on different types of milling machines. More types of cellulosic materials will be tested to see if conclusions obtained in this study can be extended to different types of cellulosic biomass. 


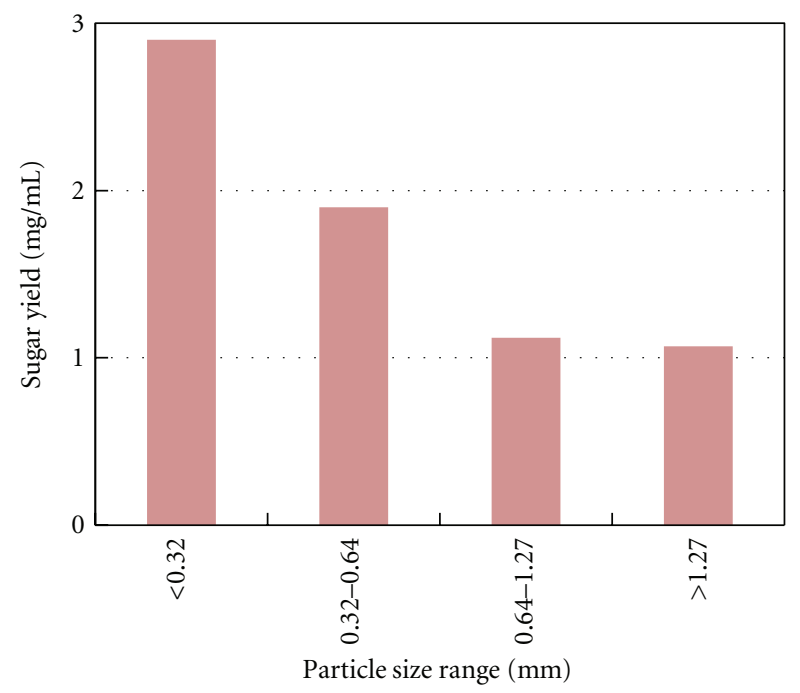

FIGURE 16: Effects of particle size on sugar yield reported by Zhu et al. [26].

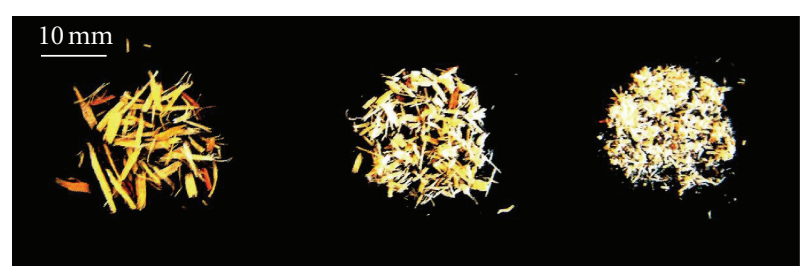

Figure 17: Wood particles processed using different sieve sizes ( sieve size $=4,2$, and $1 \mathrm{~mm}$ from left to right).

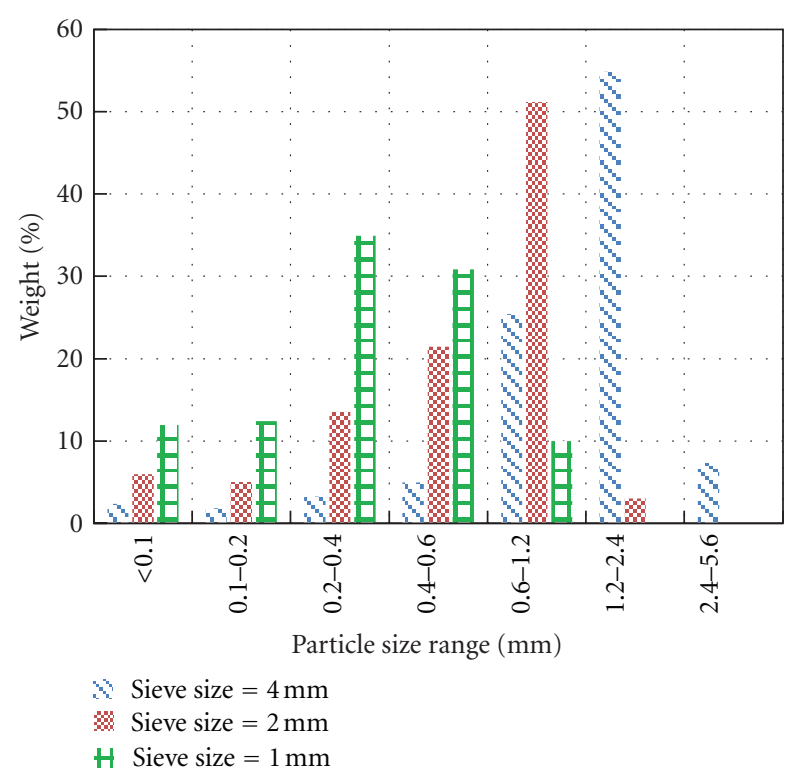

FIGURE 18: Particle size distribution.

\section{Acknowledgments}

This paper is supported by NSF award CMMI-0970112. The authors gratefully extend their acknowledgement to China Scholarship Council for the financial support to the first two authors. The authors gratefully acknowledge Mr. Feng Xu and Mr. Ke Zhang in the Department of Biological and Agricultural Engineering at Kansas State University for their support in sugar yield measurement. Thanks also go to Mr. Levi Riley, undergraduate student in the Department of Industrial and Manufacturing Systems Engineering at Kansas State University, for his help in biomass material preparation.

\section{References}

[1] Energy Information Administration, "Annual energy review 2009," Tech. Rep. DOE/EIA-0384(2009), 2010, http://www .eia.doe.gov/totalenergy/data/annual/pdf/aer.pdf.

[2] P. Moriarty and D. Honnery, "Low-mobility: the future of transport," Futures, vol. 40, no. 10, pp. 865-872, 2008.

[3] C. M. Drapcho, N. P. Nhuan, and T. H. Walker, Biofuels Engineering Process Technology, McGraw-Hill, New York, NY, USA, 2008.

[4] P. Hakkila, Utilization of Residual Forest Biomass, Springer, Berlin, Germany, 1989.

[5] R. D. Perlack, L. L. Wright, A. F. Turhollow, R. L. Graham, B. J. Stokes, and D. C. Erbach, "Biomass as feedstocks for a bioenergy and byproducts industry: the technical feasibility of a billion-ton annual supply," Tech. Rep. DOE/ GO-1020052135, Oak Ridge National Laboratory, 2005, http://feedstockview.ornl.gov/pdf/billion_ton_vision.pdf.

[6] R. D. Perlack and B. J. Stokes, "U.S. Billion-Ton Update: biomass supply for a bioenergy and bioproducts industry," Tech. Rep. ORNL/TM-2011/224, Oak Ridge National Laboratory, 2011, http://www1.eere.energy.gov/biomass/pdfs/billion_ton_update.pdf.

[7] K. A. Gray, L. Zhao, and M. Emptage, "Bioethanol," Current Opinion in Chemical Biology, vol. 10, no. 2, pp. 141-146, 2006.

[8] L. Wei, L. O. Pordesimo, C. Igathinathane, and W. D. Batchelor, "Process engineering evaluation of ethanol production from wood through bioprocessing and chemical catalysis," Biomass and Bioenergy, vol. 33, no. 2, pp. 255-266, 2009.

[9] P. Kumar, D. M. Barrett, M. J. Delwiche, and P. Stroeve, "Methods for pretreatment of lignocellulosic biomass for efficient hydrolysis and biofuel production," Industrial and Engineering Chemistry Research, vol. 48, no. 8, pp. 3713-3729, 2009.

[10] S. Paulrud, Upgraded biofuels_effects of quality on processing, handling characteristics, combustion and ash melting, Doctoral Thesis, Swedish University of Agricultural Sciences, Umeå, Sweden, 2004.

[11] L. J. Naimi, S. Sokhansanj, S. Mani et al., "Cost and performance of woody biomass size reduction for energy production," Tech. Rep. 06-107, Written for presentation in Proceedings of the Annual Conference (CSBE/SCGAB '06), Edmonton Alberta, Canada, July 2006,http://bioprocessing.ag.utk .edu/publications/2-papers_presented/csae $\% 20$ paper $\% 20$ no $\% 2006-107 \% 20$ cost $\% 20$ and $\% 20$ performance $\% 20$ of $\% 20$ woody\%20biomass_naimi\%20et\%20 al.pdf.

[12] J. W. Ranney, J. L. Trimble, L. L. Wright, and R. D. Perlack, "Short-rotation woody crops production research in the south," in Proceedings of the 3rd Southern Biomass Energy Research Conference, Gainesville, Fla, USA, March 1985. 
[13] K. W. Ragland, D. J. Aerts, and A. J. Baker, "Properties of wood for combustion analysis," Bioresource Technology, vol. 37, no. 2, pp. 161-168, 1991.

[14] A. Asikainen and P. Pulkkinen, "comminution of logging residues with evolution 910r chipper, moha chipper truck, and morbark 1200 tub grinder," Journal of Forest Engineering, vol. 9, no. 1, pp. 47-53, 1998.

[15] J. Y. Zhu and X. J. Pan, "Woody biomass pretreatment for cellulosic ethanol production: technology and energy consumption evaluation," Bioresource Technology, vol. 101, no. 13, pp. 4992-5002, 2010.

[16] S. Paulrud, J. E. Mattsson, and C. Nilsson, "Particle and handling characteristics of wood fuel powder: effects of different mills," Fuel Processing Technology, vol. 76, no. 1, pp. 23-39, 2002.

[17] G. L. Horton, D. B. Rivers, and G. H. Emert, "Preparation of cellulosics for enzymatic conversion," Industrial \& Engineering Chemistry Product Research and Development, vol. 19, no. 3, pp. 422-429, 1980.

[18] M. Mandels, L. Hontz, and J. Nystrom, "Enzymatic hydrolysis of waste cellulose," Biotechnology and Bioengineering, vol. 16, no. 11, pp. 1471-1493, 1974.

[19] M. Zhang, X. X. Song, Z. J. Pei, and D. H. Wang, "Effects of mechanical comminution on enzymatic conversion of cellulosic biomass in biofuel manufacturing: a review," in Proceedings of the ASME International Conference on Manufacturing Science and Engineering, Erie, Pa, USA, October 2010.

[20] V. Repellin, A. Govin, M. Rolland, and R. Guyonnet, "Energy requirement for fine grinding of torrefied wood," Biomass and Bioenergy, vol. 34, no. 7, pp. 923-930, 2010.

[21] D. J. Schell and C. Harwood, "Milling of lignocellulosic biomass-results of pilot-scale testing," Applied Biochemistry and Biotechnology, vol. 45-46, no. 1, pp. 159-168, 1994.

[22] Z. Miao, T. E. Grift, A. C. Hansen, and K. C. Ting, "Specific energy consumption of biomass particle production and particle physical property," in Proceedings of the ASABE Annual International Meeting, Pittsburgh, Pa, USA, June 2010.

[23] Z. Miao, T. E. Grift, A. C. Hansen, and K. C. Ting, "Energy requirement for comminution of biomass in relation to particle physical properties," Industrial Crops and Products, vol. 33, no. 2, pp. 504-513, 2011.

[24] M. Himmel, M. Tucker, and J. Baker, "Comminution of biomass: hammer and knife mills," Biotechnology Bioengineering Symposium, vol. 15, no. 15, pp. 39-58, 1985.

[25] V. S. Chang and M. T. Holtzapple, "Fundamental factors affecting biomass enzymatic reactivity," Applied Biochemistry and Biotechnology-Part A, vol. 84-86, pp. 5-37, 2000.

[26] J. Y. Zhu, G. S. Wang, X. J. Pan, and R. Gleisner, "Specific surface to evaluate the efficiencies of milling and pretreatment of wood for enzymatic saccharification," Chemical Engineering Science, vol. 64, no. 3, pp. 474-485, 2009.

[27] R. K. Dasari and R. E. Berson, "The effect of particle size on hydrolysis reaction rates and rheological properties in cellulosic slurries," Applied Biochemistry and Biotechnology, vol. 137-140, no. 1-12, pp. 289-299, 2007.

[28] C. A. Mooney, S. D. Mansfield, R. P. Beatson, and J. N. Saddler, "The effect of fiber characteristics on hydrolysis and cellulase accessibility to softwood substrates," Enzyme and Microbial Technology, vol. 25, no. 8-9, pp. 644-650, 1999.

[29] ASABE, "ASAE S358.2 DEC1988 (R2008) Moisture Measurement-Forages," 2008, http://asae.frymulti.com/azdez .asp?JID=2\&AID=24452\&CID=s2000\&T=2.

[30] P. F. Zhang, T. W. Deines, Z. J. Pei, D. Nottingham, D. H. Wang, and X. R. Wu, "Ultrasonic vibration-assisted pelleting of biomass, a designed experimental investigation on pellet quality and sugar yield," in Proceedings of the ASME International Conference on Manufacturing Science and Engineering, Erie, Pa, USA, October 2010.

[31] S. L. Herman, Electrial Studies for Trades, Delmar Cengage Learning, New York, NY, USA, 4th edition, 2009.

[32] K. C. Mary and S. O. Farrell, Biochemistry, Mary Finch Publisher, Fairfield, Conn, USA, 7th edition, 2011.

[33] L. R. Snyder, J. J. Kirkland, and D. W. Dolan, Introduction to Modern Liquid Chromatography, John Wiley \& Sons, Hoboken, NJ, USA, 2009.

[34] ASABE, "ANSI/ASAE S424.1 MAR1992 (R2007) Method of Determining and Expressing Particle Size of Chopped Forage Materials by Screening," 2008, http://asae.frymulti.com/azdez .asp? search $=1 \& \mathrm{JID}=2 \& \mathrm{AID}=23583 \& \mathrm{CID}=\mathrm{s} 2000 \& \mathrm{v}=\& \mathrm{i}=\&$ $\mathrm{T}=2$.

[35] M. Phanphanich and S. Mani, "Impact of torrefaction on the grindability and fuel characteristics of forest biomass," Bioresource Technology, vol. 102, no. 2, pp. 1246-1253, 2011.

[36] S. Mani, L. G. Tabil, and S. Sokhansanj, "Grinding performance and physical properties of wheat and barley straws, corn stover and switchgrass," Biomass and Bioenergy, vol. 27, no. 4, pp. 339-352, 2004.

[37] K. Theerarattananoon, F. Xu, J. Wilson et al., "Effects of the pelleting conditions on chemical composition and sugar yield of corn stover, big bluestem, wheat straw, and sorghum stalk pellets," Bioprocess and Biosystems Engineering, vol. 35, no. 4, pp. 615-623, 2012. 

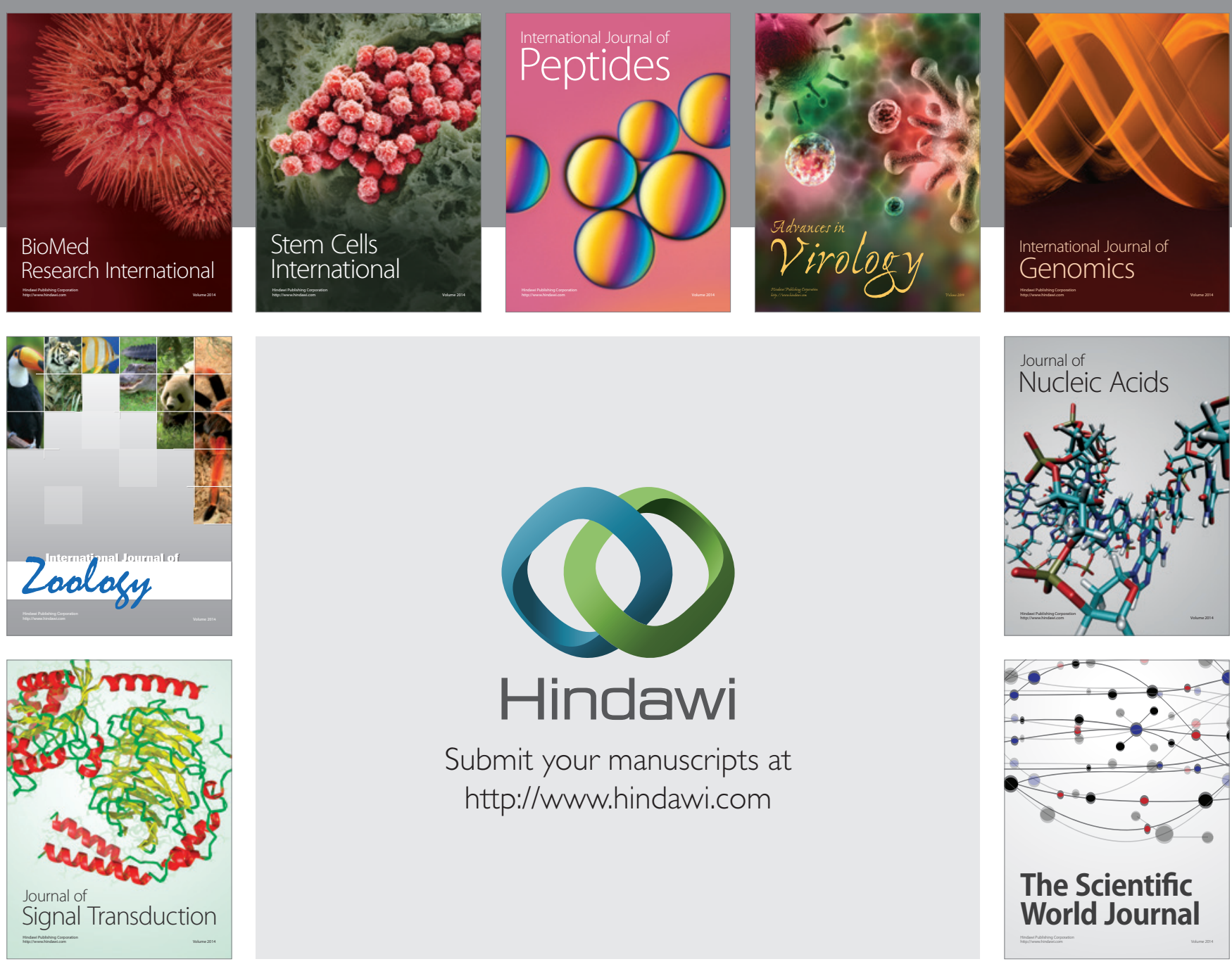

Submit your manuscripts at

http://www.hindawi.com
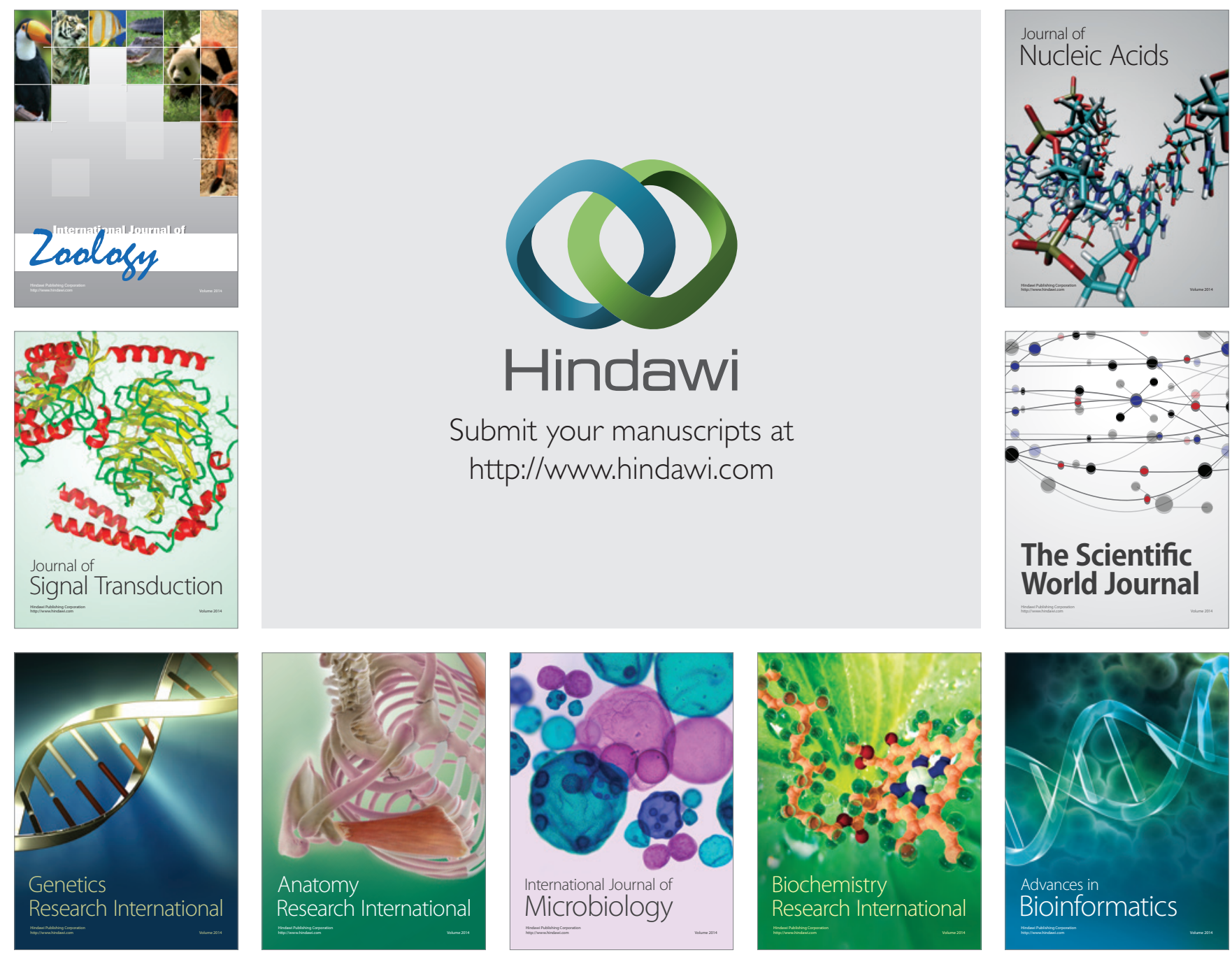

The Scientific World Journal
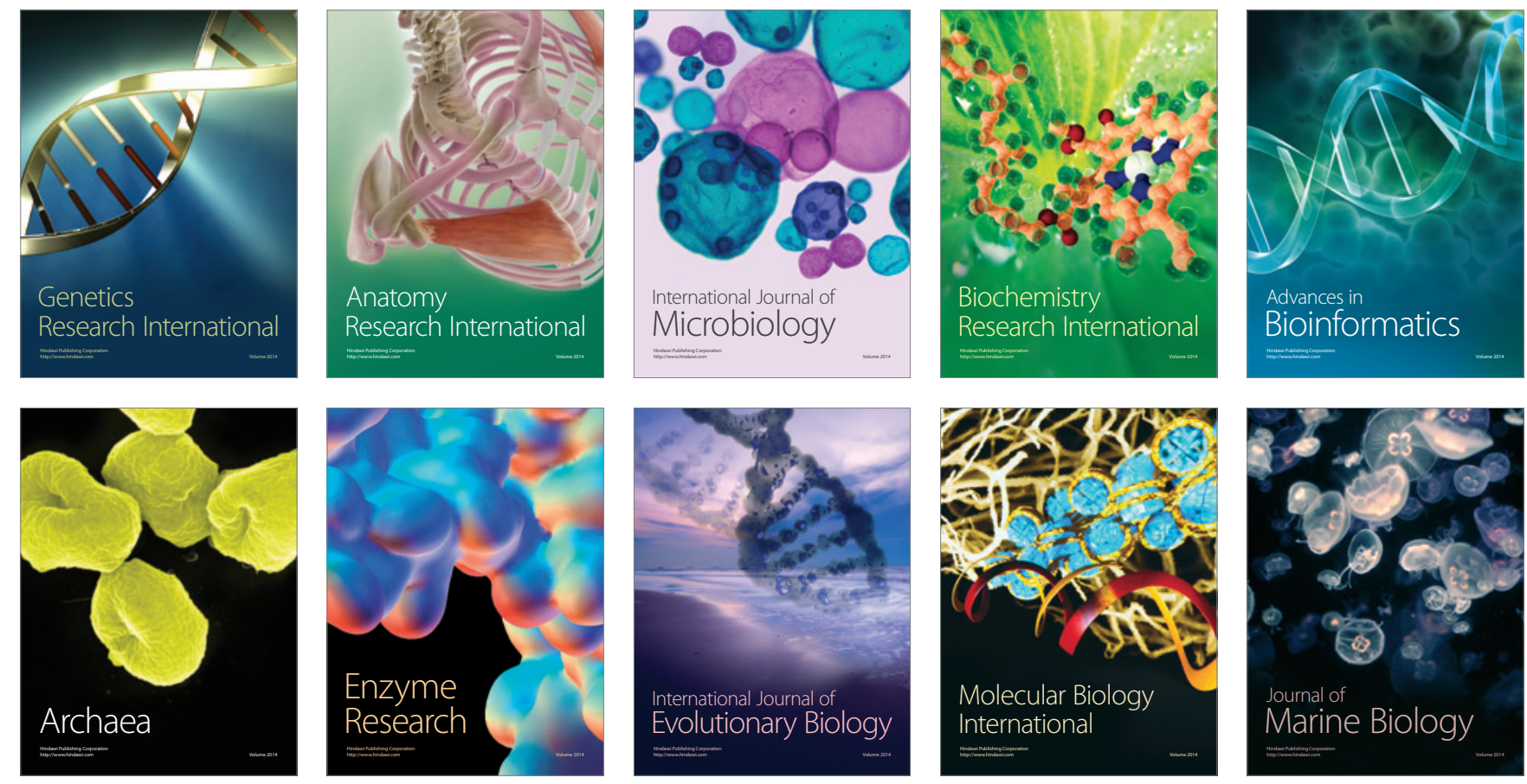